\title{
Effects of tirofiban on stent thrombosis, Hs-CRP, IL-6 and sICAM-1 after PCI of acute myocardial infarction
}

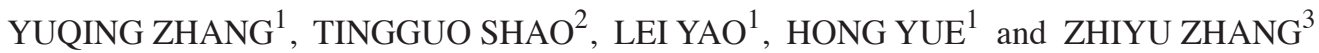 \\ ${ }^{1}$ The Second Department of Cardiology, Shouguang City People's Hospital; ${ }^{2}$ Dongcheng Branch of \\ Shouguang People's Hospital; and ${ }^{3}$ Department of Orthopedics, Shouguang City \\ People's Hospital, Weifang, Shandong 262700, P.R. China
}

Received January 5, 2018; Accepted July 27, 2018

DOI: $10.3892 / \mathrm{etm} .2018 .6589$

\begin{abstract}
Effects of tirofiban on stent thrombosis, high-sensitivity C-reactive protein (Hs-CRP), interleukin-6 (IL-6) and soluble intercellular adhesion molecule-1 (sICAM-1) after percutaneous coronary intervention $(\mathrm{PCI})$ of acute myocardial infarction (AMI) were investigated. A total of 94 AMI patients receiving PCI in Shouguang City People's Hospital from January 2016 to September 2016 were selected and randomly divided into control $(n=47)$ and observation group $(n=47)$. The control group was treated with aspirin + clopidogrel before and after operation, while the observation group was treated with tirofiban based on the treatment of control group. The postoperative stent thrombosis was compared between the two groups, and the serum Hs-CRP, IL-6 and sICAM-1 levels before operation and at 24 and $48 \mathrm{~h}$ after operation were also compared between two groups. Moreover, the incidence rates of adverse reactions in the groups were observed. Finally, patients were followed-up for 1 year to observe the total incidence rate of adverse cardiac events and life quality of patients in both groups. The thrombolysis in myocardial infarction flow grading in observation after treatment was significantly superior to that in control group $(\mathrm{P}<0.05)$. The levels of Hs-CRP, IL-6 and sICAM-1 in both groups at 24 and $48 \mathrm{~h}$ after operation were significantly decreased compared with those before operation, and they were decreased more obviously in observation group $(\mathrm{P}<0.05)$; there were no significant differences in the incidence rates of adverse reactions between the groups $(\mathrm{P}>0.05)$. Besides, the 1-year follow-up showed that the total incidence rate of adverse cardiac events in observation was significantly lower than that in control group, and the life quality scores were obviously higher than those in control group $(\mathrm{P}<0.05)$. The treatment of AMI patients undergoing
\end{abstract}

Correspondence to: Dr Yuqing Zhang, The Second Department of Cardiology, Shouguang City People's Hospital, Weifang, Shandong 262700, P.R. China

E-mail: zhangyuqingsg@126.com

Key words: acute myocardial infarction, percutaneous coronary intervention, tirofiban, thrombosis, Hs-CRP, IL-6, sICAM-1
PCI with tirofiban can effectively prevent stent thrombosis, and alleviate the inflammatory response of patients, it is safe and reliable with important clinical significance.

\section{Introduction}

With the improvement of people's living standard and the changes in dietary structure, as well as the rapid pace of life and work, the incidence rate of acute myocardial infarction (AMI) continues to increase, showing a younger trend (1). AMI is a coronary atherosclerotic disease, seriously harming human physical and mental health and reducing the life quality and survival rate of patients (2). Percutaneous coronary intervention (PCI) is one of the treatment methods of AMI, which is relatively safe, simple and less painful, thus it is widely used in clinical practice. However, the in-stent restenosis after PCI has become a major clinical problem $(3,4)$. The in-stent restenosis after PCI has close correlation with stent thrombosis, high-sensitivity C-reactive protein (Hs-CRP), interleukin-6 (IL-6) and soluble intercellular adhesion molecule-1 (sICAM1), aggravating the myocardial ischemia and hypoxia, and continuously deteriorating AMI in patients (5). Therefore, how to prevent the stent thrombosis and vascular stenosis after PCI is a hot topic in clinical research presently. In the present study, AMI patients who underwent PCI were treated with tirofiban, so as to provide a basis for the prevention and treatment of in-stent restenosis after PCI.

\section{Materials and methods}

General data. A total of 94 AMI patients treated in Shouguang City People's Hospital (Shandong, China) from January 2016 to September 2016 were selected. Inclusion criteria: i) Patients meeting the diagnostic criteria of AMI (6); ii) receiving PCI successfully for the first time; and iii) who signed the informed consent. Exclusion criteria: i) Patients accompanied by mental diseases or cognitive dysfunction; ii) AMI receiving non-PCI treatment; and iii) complicated with malignant tumors. The patients enrolled were randomly divided into control $(n=47)$ and observation group $(\mathrm{n}=47)$ using a random number table. There were no statistically significant differences in the general data of patients between two groups $(\mathrm{P}>0.05)$, and they were comparable (Table I). The study was approved by the Ethics 
Committee of Shouguang City People's Hospital (Shandong, China). Informed consents were signed by the patients or the guardians.

\section{Methods}

Medication. At 3 days before operation, patients in control group were treated with oral administration of $300 \mathrm{mg}$ aspirin enteric-coated tablets (approval: National Medicine Permission no. H20065051; Shenyang Original Pharmacy Co., Ltd.; Shenyang, China) once a day. At the same time, they took $75 \mathrm{mg}$ clopidogrel tablets (approval: National Medicine Permission no. H20000542; Shenzhen Salubris Pharmaceutical Co., Ltd.; Shenzhen, China) orally once a day to make the platelet aggregation rate $<40 \%$. They also received PCI via radial artery puncture. After operation, patients took aspirin $(100 \mathrm{mg} / \mathrm{d})$ and clopidogrel $(75 \mathrm{mg} / \mathrm{d})$ for 1 year. Based on the treatment of control, patients in observation group were treated with tirofiban (approval: National Medicine Permission no. H20060265; Hangzhou Zhongmei East China Pharmaceutical Co., Ltd.; Hangzhou, China). After the guide wire reached the stenosis during operation, $10 \mu \mathrm{g} / \mathrm{kg}$ tirofiban was injected to the relevant coronary artery infarction for more than $3 \mathrm{~min}$, followed by standard intravenous drip of $0.15 \mu \mathrm{g} /(\mathrm{kg} / \mathrm{min})$ tirofiban for $36 \mathrm{~h}$.

Sample collection. Before operation and at 24 and $48 \mathrm{~h}$ after operation, $5 \mathrm{ml}$ venous blood was drawn from patients in the two groups (fasting in the morning for more than $8 \mathrm{~h}$ ), and centrifuged at $2,300 \mathrm{xg}$ for $10 \mathrm{~min}$ at $4^{\circ} \mathrm{C}$. Then the supernatant was taken and stored in a refrigerator at $-80^{\circ} \mathrm{C}$.

Detection of Hs-CRP, IL- 6 and sICAM-1 levels. The levels of Hs-CRP and IL-6 were detected via enzyme-linked immunosorbent assay (ELISA) in strict accordance with the instructions of kits. Relevant kits were supplied by Shanghai Haoben Biotechnology Co., Ltd. (Shanghai, China). The optical density (OD) values at the wavelength of $450 \mathrm{~nm}$ were read using the microplate reader (Elx800; BioTek Instruments, Inc., Winooski, VT, USA), and the levels of Hs-CRP and IL-6 were calculated. The concentration of sICAM-1 was detected via double-antibody one-step sandwich ELISA. Relevant kits were provided by Nanjing Jiancheng Bioengineering Institute (Jiangsu, China). The OD value at the wavelength of $450 \mathrm{~nm}$ was read using the microplate reader, and the sICAM-1 level was calculated.

\section{Evaluation criteria.}

Thrombolysis in myocardial infarction (TIMI) flow grading criteria: i) Grade 0, no forward flow at the distant end of occlusive vessels; ii) grade 1, partial passing of contrast agent through the occlusion, and no filling in the distal vessels; iii) grade 2, complete passing of contrast agent through the distal vessels, its filling and removal rates $>3$ cardiac cycles, significantly slower than normal blood vessels; and iv) grade 3 , rapid filling and removal of contrast agent in distal vessels, $<3$ cardiac cycles (7).

The serum Hs-CRP, IL-6 and sICAM-1 levels in two groups were detected via ELISA before operation and at 24 and $48 \mathrm{~h}$ after operation. The incidence rates of adverse reactions in patients in both groups were compared, including severe bleeding, thrombocytopenia, abnormal liver function and gastrointestinal reactions.
Patients were followed-up for 1 year to compare the total incidence rate of adverse cardiac events between two groups, including the malignant arrhythmia, recurrent angina and heart failure. Moreover, the life quality of patients was evaluated from the physical strength (70 points), disease conditions (26 points), medical conditions (6 points), general living function (17 points), psychological function (26 points) and working conditions ( 9 points). The score was positively correlated with the life quality.

Statistical analysis. SPSS 19.0 software (SPSS, Inc., Chicago, IL, USA) was used for data processing. Measurement data are presented as mean \pm standard deviation (SD), and a t-test was used. Enumeration data are presented as rate, and Chi-square test was used. F-test was used for the intergroup differences. A $\mathrm{P}<0.05$ was considered to indicate a statistically significant difference.

\section{Results}

Comparison of TIMI flow grading between two groups. The TIMI flow grading in observation after treatment was significantly superior to that in control group $(\mathrm{P}<0.05)$ (Table II).

The levels of Hs-CRP, IL-6 and sICAM-1 in both groups after operation were significantly decreased compared with those before operation, and they were decreased more obviously in observation group $(\mathrm{P}<0.05)$ (Tables III, IV and $\mathrm{V}$ ).

Comparison of incidence rates of adverse reactions between two groups. There were no significant differences in the incidence rates of adverse reactions between the groups $(\mathrm{P}>0.05)$ (Table VI).

Comparison of total incidence rate of adverse cardiac events between two groups. The 1-year follow-up showed that the total incidence rate of adverse cardiac events in observation was significantly lower than that in control group $(\mathrm{P}<0.05)$ (Table VII).

Comparison of life quality between two groups. The 1-year follow-up showed that the life quality score in observation was obviously higher than that in control group $(\mathrm{P}<0.05)$ (Table VIII).

\section{Discussion}

AMI is usually caused by the myocardial infarction due to coronary artery occlusion induced by coronary atherosclerotic plaque rupture and thrombosis. AMI patients often suffer from atrial fibrillation and arrhythmia. When the myocardial infarct area is $\geq 20 \%$, significant hemodynamic decompensation will occur. When the infarct area is $>40 \%$, cardiac shock will occur $(8,9)$. PCI can quickly help restore the blood perfusion in coronary artery and rebuild the blood supply, but patients are prone to in-stent restenosis after PCI, which is closely related to surgery, inflammation, stent thrombosis and genetic factors (10). Therefore, PCI and early drug therapy for AMI patients are of great significance in reducing the vascular restenosis. 
Table I. Comparison of general data of patients between two groups.

\begin{tabular}{|c|c|c|c|c|}
\hline \multirow[b]{2}{*}{ Items } & \multicolumn{2}{|c|}{ Groups } & \multirow[b]{2}{*}{$\mathrm{t} / \chi^{2}$} & \multirow[b]{2}{*}{ P-value } \\
\hline & Control $(n=47)$ & Observation $(\mathrm{n}=47)$ & & \\
\hline Gender (male/female) & $26 / 21$ & $24 / 23$ & 0.043 & 0.836 \\
\hline Age (years) & $40-80$ & $40-75$ & & \\
\hline Average age (years) & $56.36 \pm 8.42$ & $55.93 \pm 7.57$ & 0.260 & 0.795 \\
\hline BMI $\left(\mathrm{kg} / \mathrm{m}^{2}\right)$ & $24.23 \pm 1.05$ & $24.56 \pm 1.18$ & 1.432 & 0.155 \\
\hline Onset time (h) & $42.57 \pm 3.64$ & $43.67 \pm 4.25$ & 1.348 & 0.181 \\
\hline \multicolumn{5}{|c|}{ History of diseases, n (\%) } \\
\hline Hypertension & $16(34.04)$ & $18(38.30)$ & 0.046 & 0.830 \\
\hline Hyperlipidemia & $11(23.40)$ & $13(27.66)$ & 0.056 & 0.813 \\
\hline Diabetes mellitus & $9(19.49)$ & 7 (14.89) & 0.075 & 0.784 \\
\hline
\end{tabular}

BMI, body mass index.

Table II. Comparison of TIMI flow grading between two groups.

\begin{tabular}{|c|c|c|c|c|c|}
\hline Groups & No. & Grade 0 & Grade 1 & Grade 2 & Grade 3 \\
\hline Observation & 47 & 14 (29.79) & $15(31.91)$ & $7(14.89)$ & $11(23.40)$ \\
\hline Control & 47 & $1(2.13)$ & $3(6.38)$ & $14(29.79)$ & $29(61.70)$ \\
\hline $\begin{array}{l}\chi^{2} \\
\text { P-value }\end{array}$ & & 29.700 & & & \\
\hline
\end{tabular}

TIMI, thrombolysis in myocardial infarction.

Table III. Comparison of Hs-CRP levels at different time points between two groups (mg/l).

\begin{tabular}{|c|c|c|c|c|c|c|}
\hline Groups & No. & Before operation & $24 \mathrm{~h}$ after operation & $48 \mathrm{~h}$ after operation & F-test & P-value \\
\hline Observation & 47 & $4.85 \pm 1.13$ & $3.02 \pm 0.61$ & $1.63 \pm 0.34$ & 39.134 & $<0.001$ \\
\hline Control & 47 & $4.72 \pm 1.18$ & $3.64 \pm 0.78$ & $2.52 \pm 0.47$ & 28.532 & $<0.001$ \\
\hline t-test & & 0.545 & 4.293 & 10.518 & & \\
\hline P-value & & 0.587 & $<0.001$ & $<0.001$ & & \\
\hline
\end{tabular}

Hs-CRP, high-sensitivity C-reactive protein.

Table IV. Comparison of IL-6 levels at different time points between two groups (ng/l).

\begin{tabular}{|c|c|c|c|c|c|c|}
\hline Groups & No. & Before operation & $24 \mathrm{~h}$ after operation & $48 \mathrm{~h}$ after operation & F-test & P-value \\
\hline Observation & 47 & $12.89 \pm 2.23$ & $7.52 \pm 1.15$ & $5.83 \pm 1.04$ & 38.716 & $<0.001$ \\
\hline Control & 47 & $12.36 \pm 2.28$ & $9.74 \pm 1.47$ & $8.79 \pm 1.15$ & 27.452 & $<0.001$ \\
\hline t-test & & 1.139 & 8.155 & 13.088 & & \\
\hline P-value & & 0.258 & $<0.001$ & $<0.001$ & & \\
\hline
\end{tabular}

IL-6, interleukin-6.

PCI for AMI patients often leads to the tearing of coronary artery intima, thereby activating platelets, resulting in slow or no-flow phenomenon in infarction-related vessels, and inducing thrombosis (11). The results of this study showed 
Table V. Comparison of sICAM-1 levels at different time points between two groups (mmol/l).

\begin{tabular}{|c|c|c|c|c|c|c|}
\hline Groups & No. & Before operation & $24 \mathrm{~h}$ after operation & $48 \mathrm{~h}$ after operation & F-test & P-value \\
\hline Observation & 47 & $145.52 \pm 9.23$ & $82.98 \pm 5.15$ & $64.84 \pm 3.04$ & 49.613 & $<0.001$ \\
\hline Control & 47 & $145.76 \pm 9.47$ & $106.89 \pm 5.27$ & $85.72 \pm 5.35$ & 23.756 & $<0.001$ \\
\hline t-test & & 0.124 & 22.246 & 23.263 & & \\
\hline P-value & & 0.902 & $<0.001$ & $<0.001$ & & \\
\hline
\end{tabular}

sICAM-1, soluble intercellular adhesion molecule-1.

Table VI. Comparison of adverse reactions between two groups, n (\%).

\begin{tabular}{lccccc}
\hline Groups & No. & $\begin{array}{c}\text { Severe } \\
\text { bleeding }\end{array}$ & Thrombocytopenia & $\begin{array}{c}\text { Abnormal liver } \\
\text { function }\end{array}$ & $\begin{array}{c}\text { Gastrointestinal } \\
\text { reactions }\end{array}$ \\
\hline Observation & 47 & $1(2.13)$ & $2(4.26)$ & $1(2.13)$ & $1(2.13)$ \\
Control & 47 & $3(6.38)$ & $4(8.51)$ & $0(0.00)$ & $2(4.26)$ \\
$\chi^{2}$ & & 0.261 & 0.178 & 0.001 & 0.001 \\
P-value & & 0.609 & 0.673 & 0.999 & 0.999 \\
\hline
\end{tabular}

Table VII. Comparison of cardiovascular events and total incidence rate between two groups.

\begin{tabular}{|c|c|c|c|c|c|}
\hline Groups & No. & $\begin{array}{l}\text { Malignant } \\
\text { arrhythmia }\end{array}$ & Recurrent angina & Heart failure & $\begin{array}{c}\text { Total incidence rate } \\
\text { of adverse cardiac events }\end{array}$ \\
\hline Observation & 47 & $1(2.13)$ & $1(2.13)$ & $1(2.13)$ & $3(6.38)$ \\
\hline Control & 47 & $6(12.77)$ & $8(17.02)$ & $5(10.64)$ & $19(40.43)$ \\
\hline$\chi^{2}$ & & & & & 13.352 \\
\hline P-value & & & & & 0.353 \\
\hline
\end{tabular}

Table VIII. Comparison of life quality between two groups.

\begin{tabular}{lcccccc}
\hline Groups & No. & $\begin{array}{c}\text { Physical } \\
\text { strength }\end{array}$ & $\begin{array}{c}\text { Disease } \\
\text { conditions }\end{array}$ & $\begin{array}{c}\text { Medical } \\
\text { conditions }\end{array}$ & $\begin{array}{c}\text { General living } \\
\text { function }\end{array}$ & $\begin{array}{c}\text { Psychological } \\
\text { function }\end{array}$ \\
\hline Observation & 47 & $62.89 \pm 3.23$ & $21.82 \pm 3.15$ & $5.83 \pm 0.74$ & $15.23 \pm 2.03$ & $23.23 \pm 3.13$ \\
conditions
\end{tabular}

that after treatment, the TIMI flow grading in observation was significantly superior to that in control group $(\mathrm{P}<0.05)$. The stent implantation had strong stimulation against blood vessels, causing microvascular reperfusion injury. After treatment, local microcirculation perfusion will still be insufficient, leading to vascular dysfunction. The forward flow in infarction-related vessels was not recovered, triggering stent thrombosis (12). Aspirin is a cyclooxygenase inhibitor that blocks the platelet aggregation through inhibiting the activity of acetylated cyclooxygenase-1 (13). Besides, clopidogrel is an adenosine diphosphate (ADP) receptor antagonist that can inhibit the binding of ADP to platelet receptors, thus blocking the platelet aggregation (14). After the application of the above two drugs, thrombosis can be avoided. Tirofiban is a highly-specific non-peptide platelet GPIIb/IIIa receptor antagonist, which can effectively block the common pathway of platelet activation and aggregation (15). The synergistic effect of the above three drugs can effectively improve the myocardial cell tissue perfusion, so that the myocardial perfusion in blood supply area is sufficient and the anti-thrombosis effect is more obvious. 
The damage of PCI to blood vessels can lead to vascular endothelial exfoliation, and release a large number of inflammatory factors (16). Serum Hs-CRP is a commonly-used inflammatory response marker in clinic, which is more sensitive than CRP and can directly reflect the inflammatory status and stability of coronary atherosclerotic plaque, and reflect the inflammatory status of AMI patients better and earlier. Besides, it can also be used as an evaluation index of cardiovascular events in AMI patients (17). IL-6 is an acute-phase reactive lymphocyte factor, as well as an important member in IL family, playing different roles in the body and promoting arteriosclerosis and thrombosis (18). This study showed that the levels of Hs-CRP and IL-6 in both groups at 24 and $48 \mathrm{~h}$ after operation were significantly decreased compared with those before operation, and they were decreased more obviously in observation than control group $(\mathrm{P}<0.05)$. This is because IL- 6 can induce the inflammatory cell adhesion and aggregation to promote inflammation, thus increasing the serum Hs-CRP level. Moreover, Hs-CRP can not only reflect the inflammatory degree, but also promote the inflammatory response and plaque rupture (19). The drug therapy effectively inhibited inflammation, and decreased the IL-6 and Hs-CRP levels. Tirofiban not only has the effect of protecting vascular endothelial function, but also can inhibit the expression of inflammatory factors, so the intraoperative and postoperative administration of tirofiban alleviates the inflammatory degree in AMI patients.

SICAM-1 is little or almost not expressed in normal blood vessels, but abundantly expressed in the blood of AMI patients, which is involved in the inflammatory response and adhesion reaction of patients after PCI, causing vasoconstriction and resulting in stent thrombosis, ultimately leading to vascular restenosis and cardiovascular events (20). The results in this study revealed that the levels of sICAM-1 in both groups at 24 and $48 \mathrm{~h}$ after operation were significantly decreased compared with those before operation, and it was decreased more obviously in observation group. The 1-year follow-up showed that the total incidence rate of adverse cardiac events in observation was significantly lower than that in control group, and the life quality scores were obviously higher than those in control group $(\mathrm{P}<0.05)$. This is because when the level of sICAM-1 is increased, the incidence rate of cardiovascular events will also rise. The tirofiban treatment can not only effectively block the platelet cross-linking and aggregation, but also inhibit the expression of inflammatory factors, chemokines and adhesion factors, thereby reducing the level of sICAM-1, improving the prognosis of patients, reducing the incidence rate of adverse cardiac events and increasing the life quality of patients.

In conclusion, the treatment of AMI patients undergoing PCI with tirofiban can effectively prevent stent thrombosis, and reduce the Hs-CRP, IL-6 and sICAM-1 levels, and it is safe and reliable. The small sample size in this study inevitably led to data bias, so the sample size still needs to be expanded to observe the long-term efficacy.

\section{Acknowledgements}

Not applicable

\section{Funding}

No funding was received.

\section{Availability of data and material}

All data generated or analyzed during this study are included in this published article.

\section{Authors' contributions}

YZ and TS contributed significantly to analysis and manuscript preparation. LY perform the analysis with constructive discussions. HY wrote the manuscript and helped with sample collection. ZZ revised it critically for important intellectual content. All authors read and approved the final manuscript.

\section{Ethics approval and consent to participate}

The study was approved by the Ethics Committee of Shouguang City People's Hospital (Shouguang, China). Informed consents were signed by the patients or the guardians.

\section{Patient consent for publication}

Not applicable.

\section{Competing interests}

The authors declare that they have no competing interests.

\section{References}

1. Woods KL, Ketley D, Agusti A, Hagn C, Kala R, Karatzas NB, Leizorowicz A, Reikvam A, Schilling J, Seabra-Gomes R, et al: Use of coronary angiography and revascularization procedures following acute myocardial infarction. A European perspective. Eur Heart J 19: 1348-1354, 1998 .

2. Cung TT, Morel O, Cayla G, Rioufol G, Garcia-Dorado D, Angoulvant D, Bonnefoy-Cudraz E, Guérin P, Elbaz M, Delarche N, et al: Cyclosporine before PCI in patients with acute myocardial infarction. N Engl J Med 373: 1021-1031, 2015.

3. Afana M, Brinjikji W, Cloft H and Salka S: Hospitalization costs for acute myocardial infarction patients treated with percutaneous coronary intervention in the United States are substantially higher than Medicare payments. Clin Cardiol 38: 13-19, 2015.

4. Bolca O, Güngör B, Özcan KS, Karadeniz FÖ, Sungur A, Köroğlu B, Bakhshyaliyev N, Yelgeç NS, Karataş B, İpek G, et al: The neutrophil-to-lymphocyte ratio is associated with baremetal stent restenosis in STEMI patients treated with primary PCI. Coron Artery Dis 26: 402-408, 2015.

5. Akin I and Nienaber CA: Treatment of coronary in-stent restenosis-evidence for universal recommendation? J Thorac Dis 7: 1672-1675, 2015.

6. Reichlin T, Cullen L, Parsonage WA, Greenslade J, Twerenbold R, Moehring B, Wildi K, Mueller S, Zellweger C, Mosimann T, et al: Two-hour algorithm for triage toward rule-out and rule-in of acute myocardial infarction using high-sensitivity cardiac troponin T. Am J Med 128: 369-379, 2015.

7. Higuma T, Soeda T, Yamada M, Yokota T, Yokoyama H, Nishizaki F, Xing L, Yamamoto E, Bryniarski K, Dai J, et al: Coronary plaque characteristics associated with reduced TIMI (Thrombolysis in Myocardial Infarction) flow grade in patients with ST-segment-elevation myocardial infarction: A combined optical coherence tomography and intravascular ultrasound study. Circ Cardiovasc Interv 9: e003913, 2016.

8. Reichlin T, Twerenbold R and Wildi K: Prospective validation of a 1-hour algorithm to rule-out and rule-in acute myocardial infarction using a high-sensitivity cardiac troponin $\mathrm{T}$ assay. CMAJ 187: e242-e253 2015. 
9. Jensen LJ, Munk K, Flyvbjerg A, Bøtker HE and Bjerre M: Soluble receptor of advanced glycation end-products in patients with acute myocardial infarction treated with remote ischaemic conditioning. Clin Lab 61: 323-328, 2015.

10. Shimonaga T, Kurisu S, Watanabe N, Ikenaga H, Higaki T, Iwasaki T, Ishibashi K, Dohi Y, Fukuda Y and Kihara Y: Myocardial injury after percutaneous coronary intervention for in-stent restenosis versus de novo stenosis. Intern Med 54: 2299-2305, 2015.

11. Baber U, Mehran R, Giustino G, Cohen DJ, Henry TD, Sartori S, Ariti C, Litherland C, Dangas G, Gibson CM, et al: Coronary thrombosis and major bleeding after PCI with drug-eluting stents: Risk scores from PARIS. J Am Coll Cardiol 67: 2224-2234, 2016

12. Kinnaird T, Yazji K, Thornhill L, Butt M, Ossei-Gerning N, Choudhury A, Mitra R and Anderson R: Post-procedural bivalirudin infusion following primary PCI to reduce stent thrombosis. J Interv Cardiol 29: 129-136, 2016.

13. Gong Y, Lin M, Piao L, Li X, Yang F, Zhang J, Xiao B, Zhang Q, Song WL, Yin $\mathrm{H}$, et al: Aspirin enhances protective effect of fish oil against thrombosis and injury-induced vascular remodelling. Br J Pharmacol 172: 5647-5660, 2015.

14. Samoš M, Fedor M, Kováŕ F, Duraj L, Stančiaková L, Galajda P, Staško J, Kubisz P and Mokáň M: Ticagrelor: A safe and effective approach for overcoming clopidogrel resistance in patients with stent thrombosis? Blood Coagul Fibrinolysis 27: 117-120, 2016.

15. Wu RC, Chou PT and Chen LK: Aspirin plus tirofiban inhibit the thrombosis induced by Russell's viper venom. Thromb J 14 (Suppl 1): 38, 2016.
16. Güngör B, Karatas MB, İpek G, Özcan KS, Canga Y, Onuk T, Keskin M, Hayıroğlu Mİ, Karadeniz FÖ, Sungur A, et al: Association of contrast-induced nephropathy with bare metal stent restenosis in STEMI patients treated with primary PCI. Ren Fail 38: 1167-1173, 2016.

17. Li H, Jiang Z, Liu X and Yang Z: Higher plasma level of STIM1, OPG are correlated with stent restenosis after PCI. Int J Clin Exp Med 8: 21089-21097, 2015.

18. Hozumi H, Russell J, Vital S and Granger DN: IL-6 mediates the intestinal microvascular thrombosis associated with experimental colitis. Inflamm Bowel Dis 22: 560-568, 2016.

19. Sakr SA, Ramadan MM and El-Gamal A: The inflammatory response to percutaneous coronary intervention is related to the technique of stenting and not the type of stent. Egypt Heart J 68: 37-43, 2016.

20. Lisowska A, Siergiejko E, Tycińska A, Knapp M, Kemona H, Musiał WJ and Dymicka-Piekarska V: sVCAM-1 concentration and carotid IMT values in patients with acute myocardial infarction-atherosclerotic markers of the presence, progress and prognosis. Adv Med Sci 60: 101-106, 2015.

(i) $\ominus$ This work is licensed under a Creative Commons Attribution-NonCommercial-NoDerivatives 4.0 International (CC BY-NC-ND 4.0) License. 